\title{
Preparation and Characterization of PA66/Alumina Composite Membrane
}

\author{
Dionisio da Silva Biron ${ }^{a}$, Patrícia Poletto ${ }^{a}$,Jocelei Duarte ${ }^{a}$, Mára Zeni \\ Carlos Pérez Bergmann ${ }^{b}$, Venina dos Santos ${ }^{a *}$ \\ ${ }^{a}$ Centro de Ciências Exatas e Tecnologia, Universidade de Caxias do Sul-UCS, \\ R. Francisco Getúlio Vargas, 1130, Petrópolis, CEP 95070-560, Caxias do Sul, RS, Brazil \\ ${ }^{b}$ Departamento de Materiais, Faculdade de Engenharia, Universidade Federal do Rio Grande do Sul- \\ UFRGS, Av. Osvaldo Aranha, 99, CEP 90035-190, Porto Alegre, RS, Brazil
}

Received: April 6, 2015; Revised: August 1, 2015

\begin{abstract}
In this study, polymer/ceramic composite membranes were prepared and characterized. The polymer used was polyamide 66 (PA66) deposited by dip coating on the inner surface of $\alpha$-alumina-based $\left(\mathrm{Al}_{2} \mathrm{O}_{3}\right)$ microporous tube. A coating on the ceramic support surface and the formation of the selective layer was analyzed by scanning electron microscopy (SEM) in membranes with one (PA-1) and two layers (PA-2). The results of mercury porosimetry showed that the deposition of the polyamide layers decreases the average pore size. The PA- 1 presented an average pore size of $0.35 \mu \mathrm{m}$, while the PA-2 presented two peaks of 0.18 and $0.56 \mu \mathrm{m}$. Both showed a superior performance than the ceramic support (pore diameter of $0.65 \mu \mathrm{m}$ ). Although, the permeate flux was higher with an impregnation membrane, the number of layers (one or two) just introduced a slight difference in pore statistical analysis. The order of rejection coefficient values for protein molecules is BSA $>$ egg albumin $>$ trypsin. The permeation tests showed that the composite membrane can be applied in ultrafiltration processes with MWCO of $69 \mathrm{kDa}$.
\end{abstract}

Keywords: composite membrane, PA66- $\alpha$-alumina membrane, permeability

\section{Introduction}

The preparation of novel organic-inorganic composite membranes with controlled properties had been a point of considerable interest over the last decade ${ }^{1}$. The combination of the advantages of polymer and ceramic membranes had attracted much attention and generated positive results in the separation processes. Membrane performance depends, among other factors, on the intrinsic properties of the material that constitutes the selective medium and the structure formed by this material exerts a major influence on its permeability ${ }^{2}$.

In many studies ${ }^{3,4}$, composite membranes were made from the blend of organic and inorganic materials for different applications. The preparation of these new membranes has shown improved permeability and selectivity characteristics. Another way of combination of organic and inorganic materials was composite membranes prepared with a thin polymer layer on a ceramic support. Such membranes have flux and the desired selectivity in addition to good mechanical stability ${ }^{5}$.

Ceramic membranes are applied in many separation processes and with ever increasing environmental demands, nowadays, porous alumina ceramic membranes should find application for liquid waste treatments but little research has been done to investigate and further optimize the environmental performance of these porous alumina ceramic membranes, which did not have the ability to remove organic contaminants at a ppb level, since the ceramic material did not present

*e-mail: vsantos2@ucs.br selective activity ${ }^{6,7}$. Therefore, many membranes have been prepared by depositing polymers on ceramic surfaces, joining together the advantages of each material. Li et al. ${ }^{8}$, prepared a tubular UF module equipped with polyvinylidene fluoride membranes modified by inorganic nano-sized alumina particles that was used to purify oily wastewater from an oil field, resulting in high flux permeate and retention of oil. Some works in which ceramic membranes were modified by depositing a thin polymer layer and application of these membranes were reported ${ }^{5-9}$.

In this study, composite membranes were prepared based on polyamide 66 (PA66) deposition on the inner surface of tubular $\alpha$-alumina ceramic support. Polyamide 66 is a semi-crystalline polymer, which possesses good thermal stability and mechanical strength, and is considered to be an important engineering thermoplastic ${ }^{10}$. It has been widely used for the development of synthetic membranes for application in various separation processes ${ }^{11}$. $\alpha$-alumina membranes were used in microfiltration and ultrafiltration processes because they are highly permeable to water, besides presenting a high resistance to the operating pressure ${ }^{12}$.

The aim of this work was to prepare PA66/ $\alpha$-alumina composite membranes by dip coating method. The effects of PA66 layer on the composite membrane were investigated by examining the pore size, morphological structure and permeability. 


\section{Experimental}

\subsection{Materials}

Tubular ceramic support substrates of alumina were obtained from Tecnicer-Celebra, São Carlos, São Paulo, Brazil. The samples, synthesized at $1450{ }^{\circ} \mathrm{C}$, have length of $210 \mathrm{~mm}$, inner diameter of $8 \mathrm{~mm}$, wall thickness of $2 \mathrm{~mm}$ and internal area of $52 \mathrm{~cm}^{2}$. PA66 from Rhodia Technyl was used. Formic acid, the solvent used for dissolving PA66, was purchased from Merck. Trypsin, egg albumin and bovine serum albumin (BSA) with molecular weights of 20, 45 and $69 \mathrm{kDa}$, respectively, were used in the molecular weight cut-off characterization experiments.

\subsection{Membrane preparation}

The membranes were prepared in triplicates by dip-coating, beginning with the deposition of the PA66 solution inside the tubular ceramic support. The PA66 solution was prepared at a concentration of $5 \%(\mathrm{w} / \mathrm{v})$ using formic acid as solvent. The ceramic tube was closed on one side and the solution kept inside the tube for 2 hours. The excess solution was removed and the tube was immersed in water for 2 hours in order to form the selective polyamide layer through a phase inversion process. The composite membrane remained for $6 \mathrm{~h}$ at $30^{\circ} \mathrm{C}$ in a vacuum oven to eliminate the excess solvent (Figure 1). This procedure was repeated to form membranes with two layers. The membranes with one and two layers were named PA-1 (ceramic support internally coated with one layer of PA66) and PA-2 (ceramic support internally coated with two layers of PA66).

\subsection{Characterization of the membranes}

\subsubsection{Porosimetry by mercury intrusion}

The average pore size was determined by analysis of mercury intrusion porosimetry. The analysis was performed in a porosimeter Autopore II/9220 Porosimeters (Micrometrics Instruments Corp.).

\subsubsection{Scanning electron microscopy (SEM) analysis}

The samples were initially fractured in liquid nitrogen and then gold-coated by sputtering for $1.5 \mathrm{~min}$. The morphology of the surface and cross section of the membranes was obtained by scanning electron microscopy-SEM ZEISS-LEICA/400.

\subsubsection{Pure water flux}

The ultrafiltration tests were performed in a bench system, as shown in Figure 2. System comprises a feed tank of 2 liters, a pumping system with a diaphragm pump with three chambers of the positive displacement motor and Permanent magnet, $\mathrm{P} / \mathrm{N}$ 11-155-05. The working flow rate used was 0.93 liters per minute with Reynolds number 2630.

Importantly, the system had two check valves, one after the gauge and the other at the beginning of bypass, which returns part of the flow that is repressed by feeding back to the pump. The first valve aimed to restrict the passage of the feed flow and cause pressure loss to increase the transmembrane pressure; the second controlled the flow in the system.
These characterization tests were performed with pure water for two hours, and each $10 \mathrm{~min}$ the permeate volume was measured. For these analysis were used three samples of each membrane and ceramic suport. The order of the pressures used were 300, 250, 200 and $150 \mathrm{kPa}$. The permeate flux was calculated according to Equation 1:

$J_{w l}=\frac{V}{A \Delta t}$

where $J_{W I}$ is the water flux $\left(\mathrm{L} \cdot \mathrm{m}^{-2} \cdot \mathrm{h}^{-1}\right), V$ is the permeated volume (L), $A$ is the inner membrane area $\left(0.0052 \mathrm{~m}^{2}\right)$, and $\Delta \mathrm{t}$ is time of permeation (h).

\subsubsection{Membrane Resistance $\left(\mathrm{R}_{\mathrm{m}}\right)$}

The membrane resistance is the resistance offered by the membrane to the feed flow. It is an indication of the osmotic limitation of the membrane due the transmembrane pressure. The membrane resistance was calculated using Equation 2:

$$
R_{m}=\frac{\Delta P}{\eta_{w} \times J_{w l}}
$$

where $R_{M}$ is the membrane resistance $\left(\mathrm{m}^{-1}\right) ; \Delta P$ is the transmembrane pressure $(\mathrm{Pa}) ; \eta_{W}$ is the viscosity of pure water $\left(8.4 \times 10^{-4} \mathrm{~Pa} \cdot \mathrm{s}\right)$.

\subsubsection{Determination of protein rejection}

The solutions of trypsin $(20 \mathrm{kDa})-$ Merck / E. Merck darmstadt, Germany, egg albumin (45 kDa) and bovine serum albumin (BSA) (69 kDa) (Inlab/Alamar Tecno-Científica Ltda) were used to determine the rejection performance of the composite membrane. All the solutions were prepared at a concentration of $100 \mathrm{ppm}$. Protein rejection was measured by reading the absorbance on the wavelength of $280 \mathrm{~nm}$ using a Genesys Ultraviolet Spectrophotometer, 10UV, Termo Spectronic (UV-Visible). The retention (\%RP) was calculated by Equation 3:

$\% R P=\left(1-\frac{C_{p}}{C_{f}}\right) .100$

where $C_{P}$ is the solute permeate concentration and $C_{F}$ is the solute feed concentration.

\subsubsection{Pore statistic}

The study of pore statistics was realized following the methodology described by Arthanareeswaran \& Thanikaivelan ${ }^{13}$. In this study, average pore size, surface porosity and pore density of membranes were calculated based on protein rejection.

The radius of the solute that showed a retention $(\% R P)$ above $90 \%$ was used to measure the average pore size of the membranes and of the ceramic support (Equation 4).

$\bar{R}=100\left(\frac{\alpha}{\% R P}\right)$

where $\alpha$ is the mean radius of the solute (45 $\AA$, relative to BSA). 


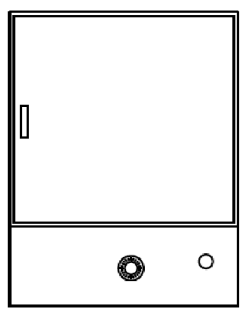

Drying of the ceramic supports $\left(110^{\circ} \mathrm{C}\right.$ and $\left.12 \mathrm{~h}\right)$
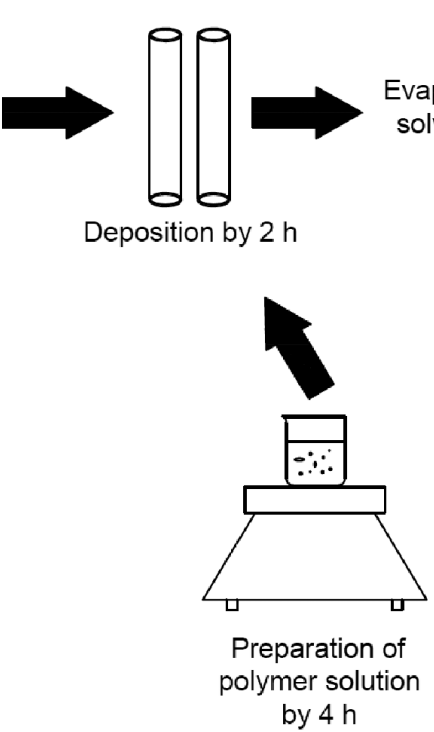

Evaporation of the solvent by $5 \mathrm{~min}$

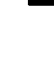<smiles>[I-]</smiles>

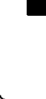

Phase inversion process $\left(23^{\circ} \mathrm{C}\right.$ and $30 \mathrm{~min})$ acuum oven $\left(30^{\circ} \mathrm{C}\right.$ and $6 \mathrm{~h}$ )
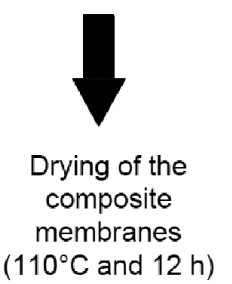
$\left(110^{\circ} \mathrm{C}\right.$ and $\left.12 \mathrm{~h}\right)$

Figure 1. Experimental methodology used in obtaining of the composite membranes PA-1 and PA2.

System bench microfiltration

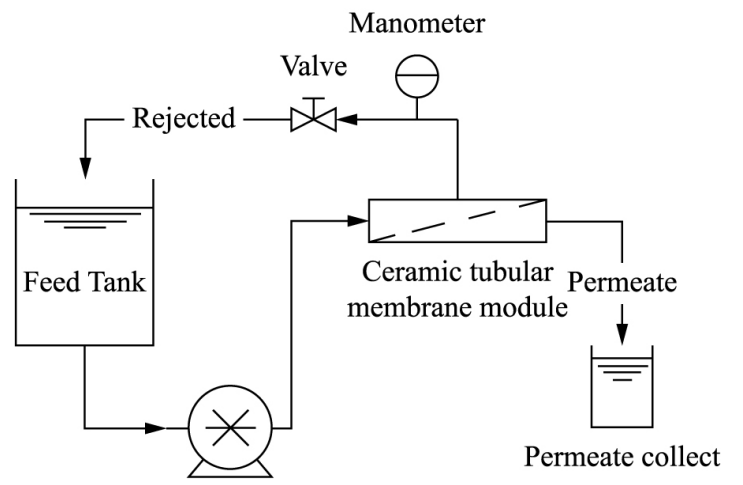

Figure 2. Microfiltration system used in separation processes.

Assuming the membrane to be asymmetric type, the surface porosity of the membrane as determined using Equation 5.

$\varepsilon=\frac{3 \pi \eta_{w} J_{w 1}}{\bar{R} \times \Delta P}$

where $\varepsilon$ is the surface porosity; $\eta_{W}$ is the viscosity of the deionized water $\left(\mathrm{g} \cdot \mathrm{cm}^{-1} \cdot \mathrm{s}^{-1}\right) ; J_{W l}$ is the pure water flux $\left(\mathrm{cm} \cdot \mathrm{s}^{-1}\right)$ and $\Delta P$ is the applied pressure $\left(\mathrm{dyn}^{\cdot} \mathrm{cm}^{-2}\right)$. From the values of $\varepsilon$ and $\bar{R}(\mathrm{~cm})$, the pore density in the membrane surface as calculated using Equation 6.

$n=\frac{\varepsilon}{\pi \times \overline{R^{2}}}$

where $n$ is number of pores $\cdot \mathrm{cm}^{-2}$.

\subsubsection{Fouling-resistance ability}

After 2 hours of permeation BSA solution, the membranes were washed with deionized water for $20 \mathrm{~min}$. Pure water flux $\left(J_{W 2}\right)$ of the cleaned membranes was measured at $200 \mathrm{kPa}$. The fouling-resistance ability of the composite membranes was evaluated by the flux recovery ratio (FRR) calculated by the following Equation $7^{13}$.

$$
F R R=\frac{J_{w 2}}{J_{w 1}} \times 100
$$

\subsubsection{Cleaning chemistry in recovering the flow}

A solution of sodium hydroxide was used to make $100 \mathrm{ppm}$ chemical cleaning of the ceramic backing and composite membranes PA-1 and PA-2. This process was performed at pressure of $100 \mathrm{kPa}$ for $2 \mathrm{~h}$ at $45^{\circ} \mathrm{C}$. Afterward systems were washed with distilled water.

\section{Results and Discussion}

\subsection{Characterization of ceramic support and PA-1 and PA-2 membranes - pore diameter and morfology}

The pore diameter (mean), Figure 3, determined by mercury porosimetry, was $0.65 \mu \mathrm{m}$ for the $\alpha$-alumina support (Figure 3a) and $0.35 \mu \mathrm{m}$ for PA-1 membrane, Figure 3b. PA-2 membrane showed a pore diameter between $0.18-0.56 \mu \mathrm{m}$, Figure $3 \mathrm{c}$. The decrease in the diameter pore of the PA-1 and PA-2 in relation to that of ceramic support confirms effective interaction occurs between the substrate and the polymer producing a selective membrane for separating the solute lower molecular weights, the results are shown as permeation experiments.

The deposition of the second layer of PA66 was performed over the first one. The insertion of this second layer, using the same procedure, led to a partial dissolution of the first layer of polyamide 66. Thus, part of the polymer was adhered to the substrate (ceramic support) and the rest was bound to the polymer. Therefore, the existence of two pore distributions $(0.18$ and $0.56 \mu \mathrm{m})$ can be explained in terms of the heterogeneity of the formed membrane. 


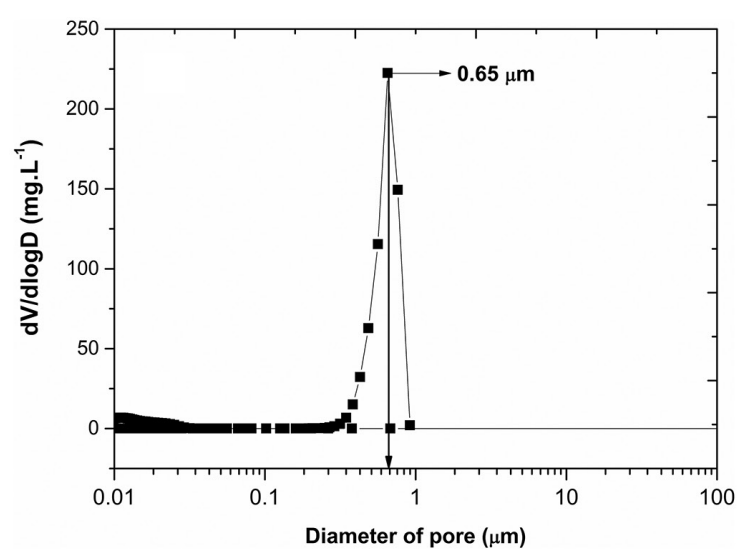

(a)

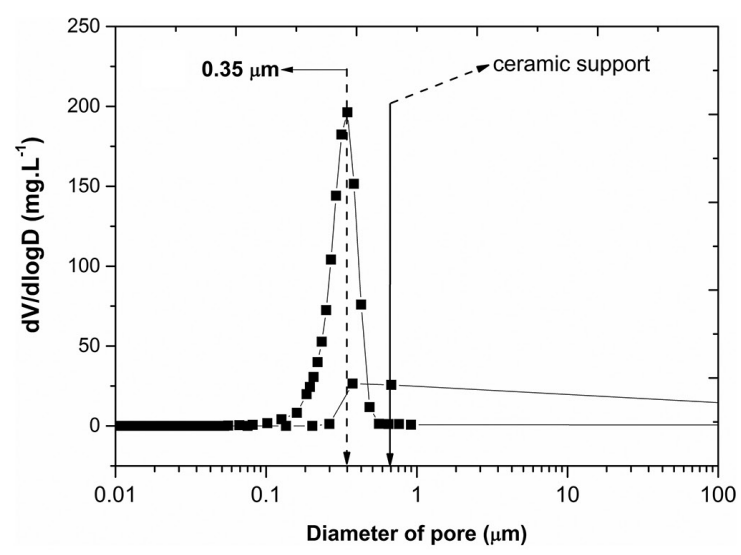

(b)

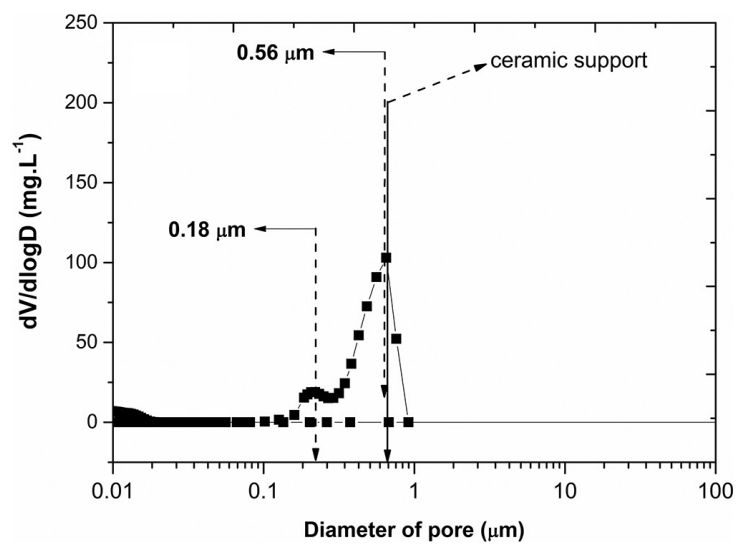

(c)

Figure 3. Pore size distribution by mercury porosimetry intrusion analysis: (a) ceramic support, (b) PA-1 and (c) PA-2.
Tsetsekou et al. (2008) ${ }^{6}$ reported that increasing the amount of polymeric layers on ceramic support of alumina systematically lowers the porosity and the average pore size follows the same trend, although affected to a lesser degree. This can be explained by the difference in interfacial tension of the polymer solution when it is applied to a bare ceramic surface or on a surface already covered by a thin layer of polymer.

The presence of PA66 can be analyzed in Figure 4. There was a crack free coating on the support surface, which must have helped reduce the pore size, as shown in mercury porosimetry. The membrane cross-section was also deposited with PA66, which reached a depth of around $10 \mu \mathrm{m}$. The membranes PA-1 and PA-2 shows a dense film without macrovoids. There was no increase in top layer thickness (PA66) to PA-2 membrane as can be seen in Figure 4f.

\subsection{Permeation experiment}

\subsubsection{Pure water flux}

According to Wei et al., the structural stability of the composite membranes depends on good adhesion between the separation layer and the ceramic support ${ }^{14}$. Based on the permeability results discussed in this paper, the composite membrane was seen to present stable behavior during the tests.

Figure 5 shows the pure water flux of the ceramic support and the composite membrane. The ceramic support presented a higher water flux, as already expected. The top layer of PA 66 in the composite membrane caused the reduction of the pure water flux at $200 \mathrm{kPa}$ from 65 to $18 \mathrm{~L} \cdot \mathrm{m}^{-2} \cdot \mathrm{h}^{-1}$, which proves that polymer deposition on the surface of the ceramic support increased resistance to water flux.

Both membranes PA-1 and PA-2, with one and two layers by dip coating process, respectively, exhibited a very similar performance, where PA-1 membrane presented a slightly higher flux. The membrane resistance $(R m)$ was calculated and presented in Table 1. The ceramic support showed the lower membrane resistance of $0.83 \times 10^{13} \mathrm{~m}^{-1}$. The composite membranes PA-1 and PA-2 presented higher membrane resistances, due to the polymer impregnation. As is observed in porosimetry analysis, the polymer impregnation decreases the pore size in the composite membranes.

\subsubsection{Determination of molecular weight cut-off and rejection}

The protein rejection of the composite membrane was determined using solutes with different molecular weight. Figure 6 shows the behavior of the composite membrane

Table 1. Values of some characterization parameters of membranes.

\begin{tabular}{|c|c|c|c|c|c|c|c|}
\hline \multirow[b]{2}{*}{ Membrane } & \multirow[b]{2}{*}{$\begin{array}{c}\text { PWF } \\
\left(\mathbf{L} \cdot \mathbf{m}^{-2} \cdot \mathbf{h}^{-1}\right)\end{array}$} & \multirow[b]{2}{*}{$\underset{\left(\times 10^{13} \mathbf{m}^{-1}\right)}{\operatorname{Rm}}$} & \multirow[b]{2}{*}{ aFRR (\%) } & \multirow[b]{2}{*}{$\begin{array}{c}{ }^{\mathrm{b}} \mathrm{FRR} \\
\text { (\%) }\end{array}$} & \multicolumn{3}{|c|}{ Pore statistics } \\
\hline & & & & & $\begin{array}{c}\text { Average pore } \\
\text { radius R (Á) }\end{array}$ & $\begin{array}{l}\text { Surface } \\
\text { porosity } \\
\varepsilon \times 10^{-5}\end{array}$ & $\begin{array}{c}\text { Number of } \\
\text { pores }{ }^{-c^{-2}} \\
\eta \times 10^{7}\end{array}$ \\
\hline Support & 65 & 0.83 & 57.4 & 100 & 55.4 & 20.4 & 21.1 \\
\hline PA-1 & 18 & 2.9 & 52.8 & 100 & 48.4 & 6.48 & 8.81 \\
\hline PA-2 & 15 & 2.8 & 37.3 & 100 & 45.9 & 5.7 & 8.61 \\
\hline
\end{tabular}

${ }^{a}$ Tratament only with water. ${ }^{\text {b}}$ Tratament with solution of sodium hydroxide (1\%). 

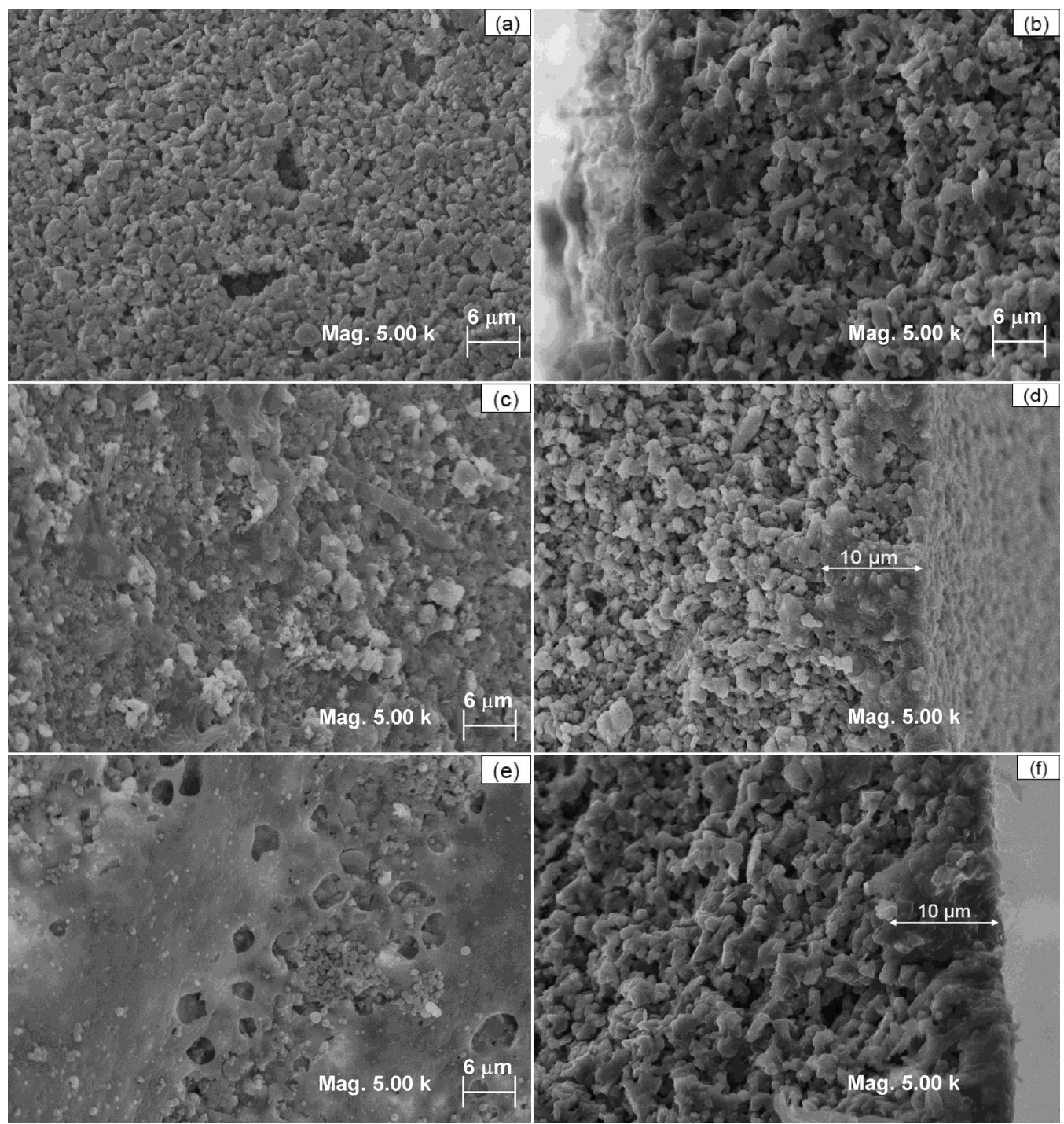

Figure 4. Micrographs obtained by SEM: (a) support surface, (b) support cross section, (c) surface of the membrane with one layer by dip coating process, (d) cross section of the membrane with one layer by dip coating process, (e) surface of the membrane with two layers by dip coating process and (f) cross section of the membrane with two layers by dip coating process.

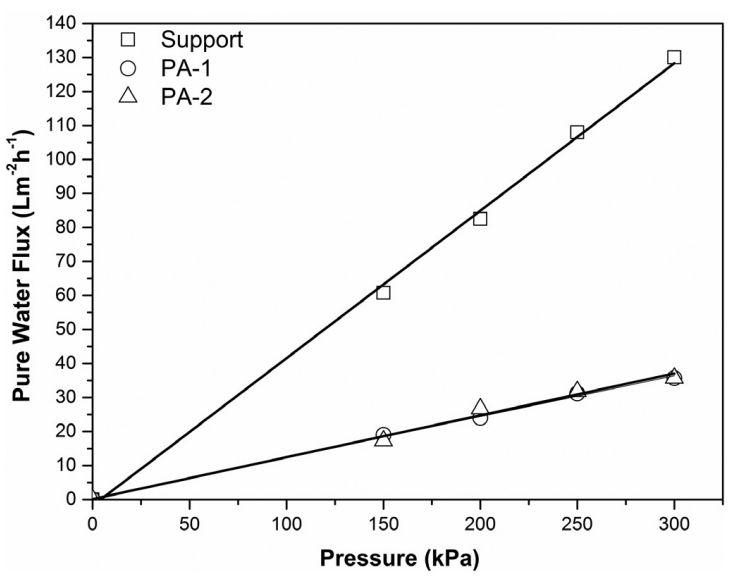

Figure 5. Pure water flux of the support and composite membranes. during the permeation test. Similar results demonstrated ceramic tube permeate flux obtained by Colle et al. (2007) in their experiments for oil retention for a pore size of approximately $0.5 \mu \mathrm{m}^{15}$. The permeate flux decreased as the molecular weight of the solute increased, i.e., the smaller the molecular weight the more easily the molecule passes through the membrane. The order of intensity of flux decline was verified for experiments with BSA $>$ egg albumin $>$ trypsin. This may be due to the decreasing molecular weights of BSA, egg albumin and trypsin which are 69,45 and $20 \mathrm{kDa}$, respectively.

From permeate flux data, one can perceive average flux decrease and flux permeate decline during the filtration. The reason for a more intense decrease in average flux observed with the filtration of a protein solution with a higher weight can be interpreted based on total blockage of some 


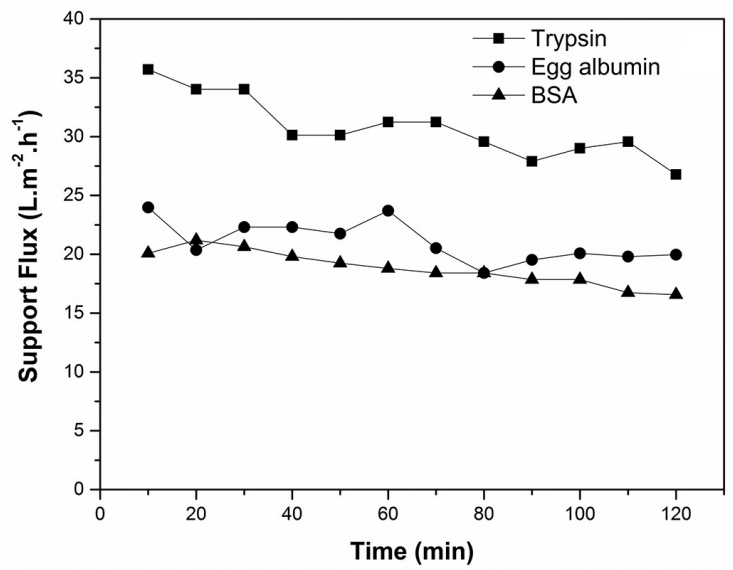

(a)

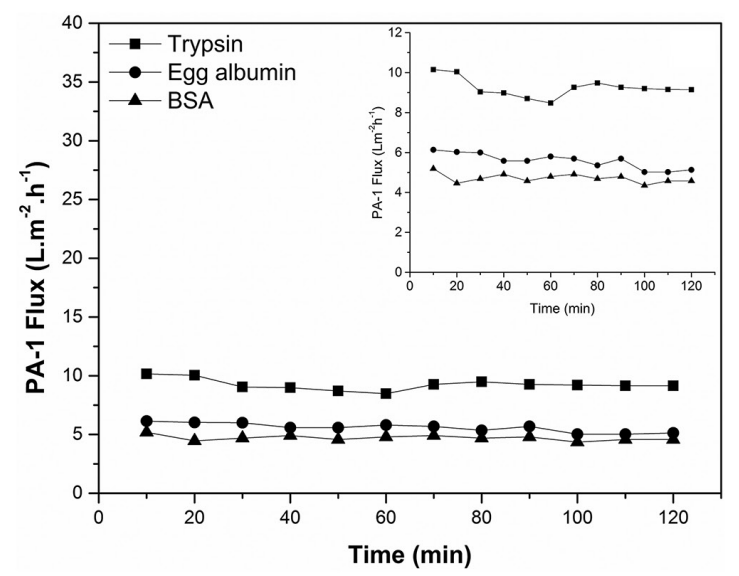

(b)

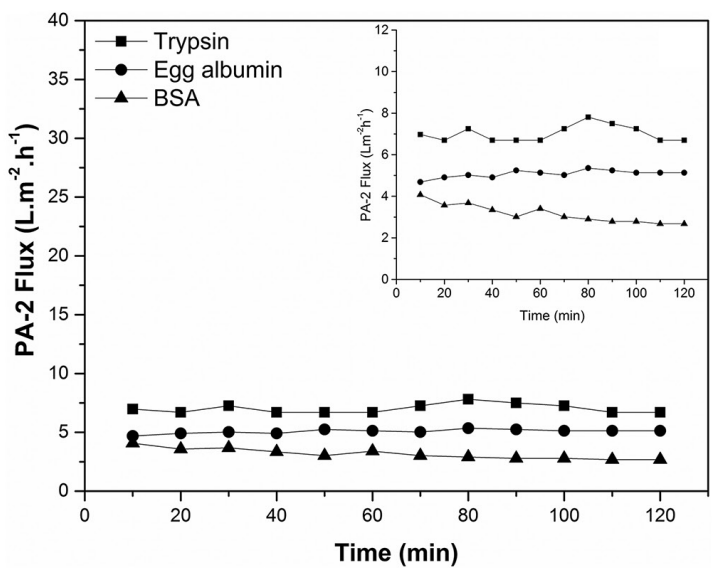

(c)

Figure 6. Protein permeate flux of the support (a) and composite membranes PA-1 (b) and PA-2 (c).

pores or due to an increase of a molecular layer of adsorbed protein on the inner surface of pores of membranes.

In Figure 7, protein rejection is shown as a function of the protein solute and membrane type. For both membranes, BSA was found to have higher rejection among the proteins studied. The support presented rejection of around 56 to $81 \%$ for trypsin and BSA, respectively. For PA-1 and PA-2 membranes, BSA rejection reached 93 and $98 \%$, respectively.

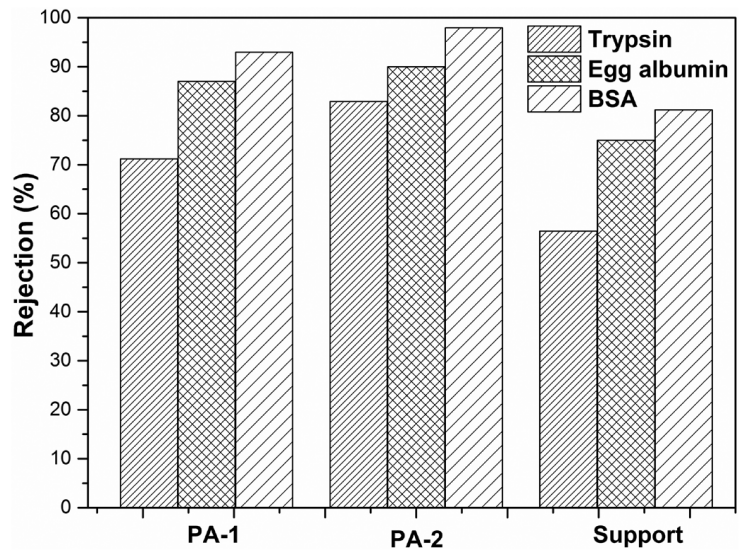

Figure 7. The influence of polymer deposition in protein rejection.

Nandi et al. ${ }^{16}$ showed that the flux the membrane decreased and BSA rejection increased with an increase in both dip-coating time and cellulose acetate (CA) concentration. In three minutes of dipping time was observed rejection of $42 \%$ and $50 \%$ to $6 \mathrm{wt} \%$ and $8 \mathrm{wt} \% \mathrm{CA}$ respectively. This ceramic composite membrane was found to be formed by blockage of ceramic support matrix (formation of intermediate layer) followed by deposition of CA over the support (formation of top layer). The increasing of the polyamide 66 layer on the ceramic support allowed a reduction in the pore size of the membranes obtained in this work. The thickness of the selective layer creates resistance to passage of the permeate flux and how much thicker the polymer layer larger the transmembrane pressure required in the separation processes ${ }^{6}$.

According Levänen et al. ${ }^{17}$, various physical phenomena occurring during dip coating. When dip-coating process was initiated, instantaneously CA solution tends to penetrate through the porous structure of support surface to yield an intermediate layer. This intermediate layer played an important role in membrane durability and bonding of the top layer with the ceramic support. The structural and morphological properties of the intermediate layer were largely dependent on the pore size and porosity of the support as well as concentration of CA used for dip coating. The growth of the CA top layer was anticipated after the formation of the intermediate layer. CA top layer growth rate was also largely dependent on the CA concentration in the solution, structure and morphology of the intermediate layer ${ }^{18,19}$. Thus, the increase of the polymer layer on the ceramic support is an important mechanism that influences in the heterogeneity of selective layer and in the distribution of pore size.

\subsubsection{Pore statistics}

Based on the permeability experiment with the proteins, the mean pore radius could be determined as approximately $45 \AA(4.5 \mathrm{~nm})$, which is the size of the BSA molecule (Table 1). The pore size measured by the ultrafiltration method is related to the high retention obtained by the polymeric top layer, which is the selective membrane layer.

The surface porosity and the number of pores, showed the same trend, with lower values to the composite membranes. 
Again, the polymer impregnation reduced significantly the surface porosity and the pore number.

The number of layers by dip coating process (one and two) presented a slight difference in pore statistical analysis. The same behavior showed in BSA rejection, where the rejection was above $90 \%$.

Thus, the number of layers by dip coating process must be responsible for reducing the pore size, as well as the complete block of the micro-channels (pores) available for permeation. The effect of pore size reduction with polymer layers on the ceramic support can directly influence membrane selectivity and determine the most appropriate separation processes $^{15-20}$.

\subsubsection{Flux recovery ratio (FRR)}

In separation and purification processes, the fouling is caused mainly by protein adsorption in membrane surface and membrane pore ${ }^{12}$. In this experiment, water was used to clean the membranes for 20 minutes. The FRR was 57.4 e $52.8 \%$ for support and PA-1 membrane, respectively. The PA-2 membrane presented a lower FRR, around 37.3\%. After cleaning chemistry with sodium hydroxide (1\%) was observed full recovery of the permeate flux for all membranes tested (100\%), Table 1.

The cleaning with pure water was unable to remove the protein deposited on the surface and pores of the membrane.

\section{References}

1. Maximous N, Nakhla G, Wong K and Wan W. Optimization of A12O3/PES membranes for wastewater filtration. Separation and Purification Technology. 2010; 73(2):294-301. http:// dx.doi.org/10.1016/j.seppur.2010.04.016.

2. Zhang Y, Jin Z, Shan X, Sunarso J and Cui P. Preparation and characterization of phosphorylated Zr-doped hybrid silica/PSF composite membrane. Journal of Hazardous Materials. 2011; 186(1):390-395. http://dx.doi.org/10.1016/j.jhazmat.2010.11.016. PMid:21122987.

3. Khan MA, Kumar M and Alothman ZA. Preparation and characterization of organic-inorganic hybrid anion-exchange membranes for electrodialysis. Journal of Industrial and Engineering Chemistry. 2015; 21:723-730. http://dx.doi. org/10.1016/j.jiec.2014.04.002.

4. Ahmad J and Hägg M. Preparation and characterization of polyvinyl acetate/zeolite 4A mixed matrix membrane for gas separation. Journal of Membrane Science. 2013; 427:73-84. http://dx.doi.org/10.1016/j.memsci.2012.09.036.

5. Nataraj SK, Roy S, Patil MB, Nadagouda N, Rudzinski WE and Aminabhavi TM. Cellulose acetate-coated $\alpha$-alumina ceramic composite tubular membranes for wastewater treatment. Desalination. 2011; 281:348-353. http://dx.doi.org/10.1016/j. desal.2011.08.016.

6. Tsetsekou A, Arkas M, Kritikak A, Simonetis S and Tsiourvas D. Optimization of hybrid hyperbranched polymer/ceramic filters for the efficient absorption of polyaromatic hydrocarbons from water. Journal of Membrane Science. 2008; 311(1-2):128-135. http://dx.doi.org/10.1016/j.memsci.2007.12.017.

7. Dong Y, Lin B, Zhou J, Zhang X, Ling Y, Liu X, et al. Corrosion resistance characterization of porous alumina membrane
That is, the recovery rate of permeate flux can be considered low, necessitating the use of appropriate cleaning procedures.

\section{Conclusion}

The ceramic support has pore size $0.68 \mu \mathrm{m}$. PA-1 membrane (one layer PA66) and PA-2 membrane (two layers of PA66) showed a pore diameter of $0.35 \mu \mathrm{m}$ and between $0.18-0.56 \mu \mathrm{m}$, respectivamente. Membrane has a dense film of PA66 without macrovoids on the ceramic support.

The composite membranes presented stable behavior during the permeation tests, indicating that there was good adhesion between the polymer and the ceramic support. The reduction of the mean pore size and the permeate flux due to the incorporation of PA 66 increased the composite membrane selectivity.

The membrane with one layer by dip coating process (PA-1) was efficient, with over $90 \%$ rejection for BSA, with the advantage of higher permeate flux when compared with the membrane with two layers (PA-2). The permeation tests showed that the composite membrane can be applied in ultrafiltration processes with MWCO of $69 \mathrm{kDa}$.

\section{Acknowledgements}

The authors would like to acknowledge the CNPq, CAPES for financial support.

supports. Materials Characterization. 2011; 62(4):409-418. http://dx.doi.org/10.1016/j.matchar.2011.01.012.

8. Li YS, Yan L, Xiang CB and Hong LJ. Treatment of oily wastewater by organic-inorganic composite tubular ultrafiltration (UF) membranes. Desalination. 2006; 196(1-3):76-83. http:// dx.doi.org/10.1016/j.desal.2005.11.021.

9. Mittal P, Jana S and Mohanty K. Synthesis of low-cost hydrophilic ceramic-polymeric composite membrane for treatment of oily wastewater. Desalination. 2011; 282:54-62. http://dx.doi. org/10.1016/j.desal.2011.06.071.

10. Rosato DV and Dominick V. Reinforced plastics handbook. 3rd ed. New York: Elsevier Advanced Technology; 2004.

11. Lin D-J, Chang C-L, Lee C-K and Cheng L-P. Fine structure and crystallinity of porous Nylon 66 membranes prepared by phase inversion in the water/formic acid/Nylon 66 system. European Polymer Journal. 2006; 42(2):356-367. http://dx.doi. org/10.1016/j.eurpolymj.2005.07.007.

12. Basile A. Handbook of membrane reactors. Oxford: Woodhead Publishing Limited; 2013. Reactor Types and Industrial Applications 2.

13. Arthanareeswaran $\mathrm{G}$ and Thanikaivelan P. Fabrication of cellulosezirconia hybrid membranes for ultrafiltration applications: performance, structure and fouling analysis. Separation and Purification Technology. 2010; 74(2):230-2355. http://dx.doi. org/10.1016/j.seppur.2010.06.010.

14. Wei W, Xia S, Liu G, Gu X, Jin W and Xu N. Interfacial adhesion between polymer separation layer and ceramic support for composite membrane, Materials. Interfaces and Eletrochemical Phenomena. 2010; 56:1584-1592.

15. Del Colle R, Longo E and Fontes SR. Demulsification of water/ sunflower oil emulsions by a tangential filtration process using 
chemically impregnated ceramic tubes. Journal of Membrane Science. 2007; 289(1-2):58-66. http://dx.doi.org/10.1016/j. memsci.2006.11.048

16. Nandi BK, Uppaluri R and Purkait MK. Effects of dip coating parameters on the morphology and transport properties of cellulose acetate-ceramic composite membranes. Journal of Membrane Science. 2009; 330(1-2):246-258. http://dx.doi. org/10.1016/j.memsci.2008.12.071.

17. Levänen E, Mäntylä T, Mikkola P and Rosenholm JB. Layer buildup on two-layered porous substrate by dip-coating: modeling and effect of additives on growth rate. Journal of Colloid and Interface Science. 2000; 230(1):186-194. http:// dx.doi.org/10.1006/jcis.2000.7018. PMid:10998304.
18. Song KM and Hong WH. Dehydration of ethanol and isopropanol using tubular type cellulose acetate membrane with ceramic support in pervaporation process. Journal of Membrane Science. 1997; 123(1):27-33. http://dx.doi.org/10.1016/S03767388(96)00198-6.

19. Ki Hong Y and Hong WH. Influence of ceramic support on pervaporation characteristics of IPA/water mixtures using PDMS/ceramic composite membrane. Journal of Membrane Science. 1999; 159(1-2):29-39. http://dx.doi.org/10.1016/ S0376-7388(99)00050-2.

20. Del Colle R, Fortulan CA and Fontes SR. Manufacture of ceramic membranes for application in demulsification process for cross-flow microfiltration. Desalination. 2009; 245(1-3):527532. http://dx.doi.org/10.1016/j.desal.2009.02.016. 